\title{
Inventario que contiene instrumentos y papeles de música, México, 1782
}

\section{Inventorie Containing Musical Instruments and Music Papers, Mexico, 1782}

José Antonio Guzmán Bravo

Universidad Nacional Autónoma de México santris2005@yahoo.com.mx ORCID iD: https.//orcid.org/0000-0001-9084-8280

\section{RESUMEN}

Descripción de un documento que consigna un inventario de papeles de música e instrumentos musicales en la Ciudad de México (1782), que pertenecieron a don Miguel de Berrio, marqués del Jaral, rico y prominente aristócrata novohispano. Se mencionan instrumentos (especialmente violines) de los mejores constructores de la época. Los "papeles de música" muestran un repertorio de música instrumental de autores que circulaban en Nueva España a mediados del siglo XVIII y de la práctica musical en los salones aristocráticos de la nobleza novohispana. Conocimiento y popularidad de la música barroca y galante italiana y española.

Palabras clave: Música italiana, barroco novohispano, repertorio aristocrático, inventario musical, México. 


\title{
INVENTARIO QUE CONTIENE INSTRUMENTOS Y PAPELES DE MÚSICA,
}

MÉXICO, 1782

\begin{abstract}
Description of a document refering to musical instruments and music papers in Mexico City (1782), left along other personal goods that belonged to Miguel de Berrio, Marqués del Jaral, dotated amateur on the violin, rich aristocrat. Composers known in New Spain around the midle of XVIIIth century. Musical practice in the aristocrathic parlors of novohispanic nobility. The popularity and knoledge of Italian and Spanish barroque and pre-clasic repertoires in México.
\end{abstract}

Key Words: Italian music, Barroque in New Spain, Aristochratic Repertoire, Musical Inventory, Mexico.

Guzmán Bravo, J. A. (2020). Inventario que contiene instrumentos y papeles de música, México, 1782. Cuadernos de Investigación Musical, 9, pp. 84-105.

\section{INTRODUCCIÓN}

Hace algún tiempo recibí un juego de fotocopias, que reproducen un interesante y desconocido documento que fue confiado a mi escrutinio musicológico. El documento en cuestión es la Memoria de los bienes que existen por no haverse podido vender de los q[u]e quedaron [por la] muerte del Sor. Marqués del Jaral y se aplicaron à la Sra. Condeza su muger el día 31 de Julio de 1782 en q[u]e se bizo la división de caudales'.

\footnotetext{
${ }^{1}$ Esta memoria, consta de 17 páginas sin numerar de $20 \mathrm{cms}$ x $28 \mathrm{cms}$. La memoria perteneció a don Oliverio García de Moncada, descendiente de las familias de Jaral de Berrio y Moncada. Es un manuscrito en tinta negra sin numeración aunque algunos apartados tengan una secuencia numérica. He optado por agregar acentos, comas y alguna puntuación imprescindibles para la clara comprensión del documento. Agradezco a Guillermo Tovar de Teresa (q.p.d), poseedor de La memoria, la comunicación de este documento y sus valiosos comentarios contextuales. Actualmente La memoria se encuentra, con parte de su acervo bibliográfico, en el fondo documental del Consejo de la Crónica de la Ciudad de México, CCCM.
} 


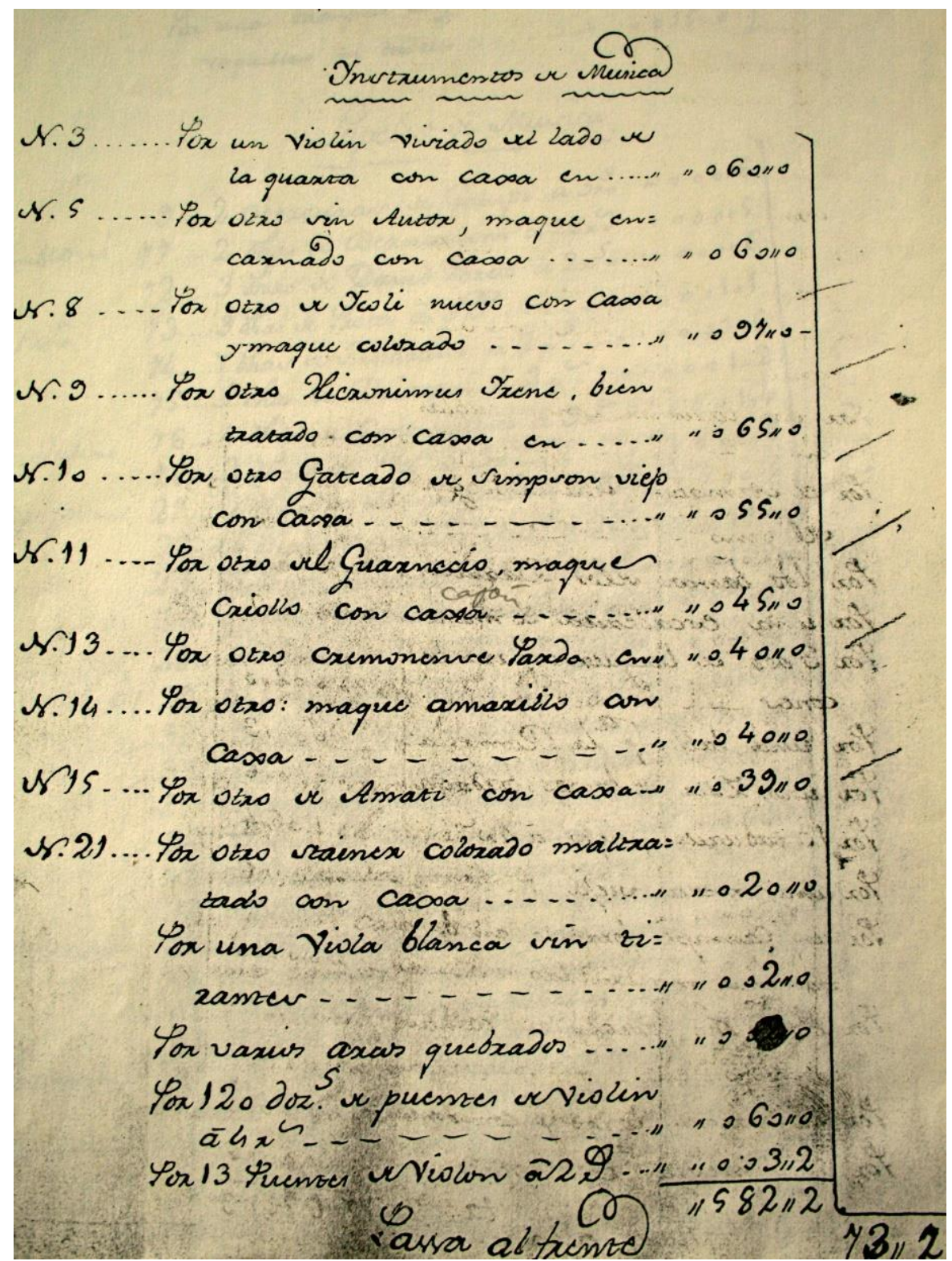

Fig. 1: Memoria de los bienes, (instrumentos de música), fragmento del manuscrito.

Esta Memoria de adjudicación de bienes por herencia, tras la muerte de don Miguel de Berrio y Saldivar, marqués del Jaral, conde de San Mateo Valparaíso (1716-1779), criollo, consejero de la Real Hacienda, contador de la Audiencia de México, Mayor de la ciudad y caballero de la Orden de Santiago, rico terrateniente con haciendas y minas en Guanjuato y Zacatecas, constituye un testimonio poco común de la cultura musical profana en la Ciudad de México en el ámbito de la aristocracia criolla durante el siglo XVIII. 


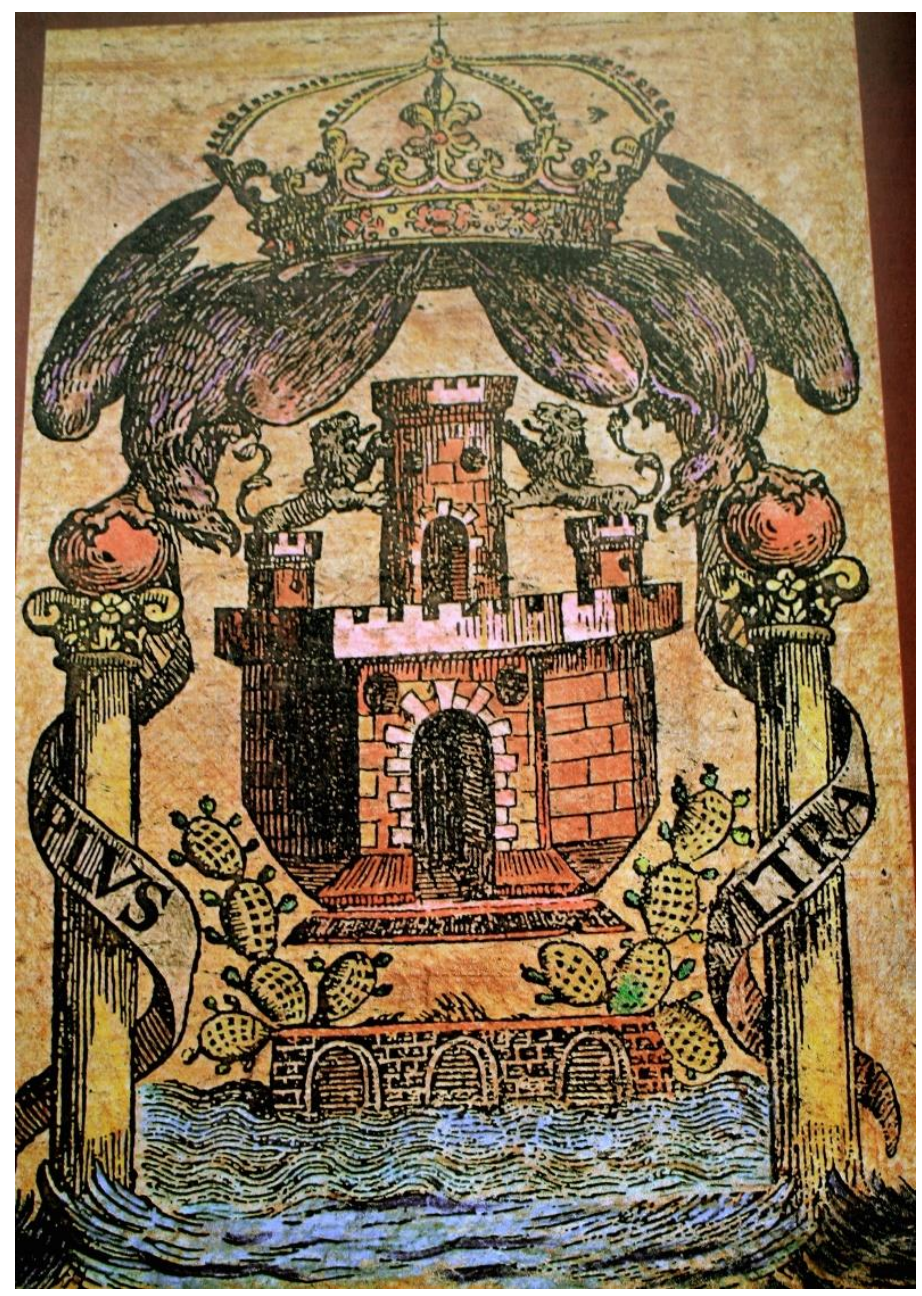

Fig. 2: Escudo de la muy noble, leal e imperial Ciudad de México, Museo de Historia del Castillo de Chapultepec.

Este inventario es posterior al que se leyó el 31 de julio de 1782 en que se hizo la división de caudales y que llevan los números 13, Memoria de los instrumentos musicales que quedaron por muerte del Señor Conde de San Mateo, Marqués del Jaral de Berrio, valuados por don Anastacio Orozco y el Nº.14, Memoria de las piezas de música que quedaron por la muerte del Señor Conde de San Mateo, Marqués del Jaral de Berrio, valuadas por don Ignacio Pedroza. ${ }^{2}$

Estas dos Memorias son ampliamente comentadas en el "Proyecto Final" Música instrumental del siglo XVIII en la Nueva España. Memorias de instrumentos musicales y piezas de música del marqués de Jaral, realizado por Alejandro Correa Rodríguez para la ESMUC, Universitat Autònoma de Barcelona. ${ }^{3}$

\footnotetext{
${ }^{2}$ Este inventario se encuentra en el Archivo Histórico Banamex, Catálogo de documentos del Fondo Marqueses de Jaral de Berrio, Expediente MJB-01-010-073, de 1782.

3 Agradezco al maestro Javier Artigas la comunicación de este valioso trabajo tan íntimamente ligado a la Memoria que aquí se comenta.
} 


\section{JosÉ ANTONIO GUZMÁN BRAVO}

En realidad la Memoria que aquí comento es un manuscrito derivado de los anteriormente citados, que presentan los listados íntegros antes de ser puestos a la venta. En la presente Memoria se listan solamente los que existen por no baberse podido vender...y se aplicaron à la Sra. Condeza, su muger. Se recomienda acudir al acucioso trabajo de Correa (2014) para una comprensión íntegral del contenido, ubicación de los lauderos, contexto social y compositores mencionados. La parte del manuscrito que comento consta solamente de 3 fojas de $30 \times 21 \mathrm{cms}$., papel indiano, tinta ferrogálica y la misma caligrafía del escribano de las 7 hojas de las memorias descritas por Correa.

Comienza la inusual enumeración de bienes que no se babian podido vender por una lista de finas joyas con diamantes perlas, corales y otras piedras preciosas, seguida de dos apartados consignando el oro y la plata bajo formas y usos diversos, que llegaron a alcanzar un valor en subasta de más de 5,000 pesos. Sigue el documento detallando relojes, instrumentos matemáticos, libros, cristalería de fino gusto y pinturas religiosas e históricas de gran interés. La Ropa entre la que consideran una alfombra y un dosel, coxin y zilla, todo en terciopelo carmesí, con galón y fleco de oro, tapete, tarima y retrato del Rey ${ }^{4}$ todo un terno de estrado real para el salón de cualquier palacio a un precio de 295 pesos. En esta heterogénea almoneda, no faltan los esclavos: Por un mulato de color cocho iamado Domingo de 36 años nacido en el Jaral en 80 pesos. Por otro llamado Pasqual de 24 años nacido en el Jaral...100.00. Estos se ballan en el obraje de Dn. José Razo hasta desquitar su valor y quedar libres.

Bajo el subtítulo de Madera, pasa a describir un variado e interesante mobiliario, hasta por fin llevarnos a los apartados que son objeto del presente comentario.

\section{INVENTARIO MUSICAL}

Aunque en total el primer apartado apenas sume los 605 pesos y 12 reales y el segundo alcance sólo 311 pesos con un real, la importancia de este testimonio sobre algunos aspectos del repertorio profano en el barroco novohispano, lo hace sumamente valioso como ilustración del tipo de música apreciada en México durante el siglo XVIII, al menos en el sector minúsculo de los ricos mayorazgos agrícolas del Virreinato.

Mientras que la mayoría de los nobles eran conocidos por sus palacios, su magnifico mobiliario, sus espléndidos caballos y mulas, sus armas, sus diamantes y perlas, únicamente dos familias tenían bibliotecas relativamente buenas. La mejor en el México colonial era la de la familia Fagoaga...la otra biblioteca famosa...perteneció al marqués de Rayas (Ladd, 1984, pp. 99-100).

Habrá que agregar a esta lista la notable biblioteca musical del Jaral de Berrio, la escogida colección de partituras y tratados del Dr. José Ignacio Bartolache, las partituras consignadas en el avalúo de la tienda de música de Fernández Jáuregui. Otras bibliotecas en la Ciudad de México con ricos fondos musicales fueron la Turriana de la Catedral de México, las de la Compañía de Jesus (Colegio Mayor de San Pedro y San Pablo, San Ildefonso, la Casa

\footnotetext{
${ }^{4}$ Ibid.

${ }^{5}$ Ibid. 
Profesa, Colegio de Tepotzotlán), la del Convento de San Francisco, que se enriqueció notablemente tras la expulsión de los jesuitas y la posterior venta de sus acervos, llegando a ser a fines del siglo XVIII considerada la más rica del virreinato con 16, 417 volúmenes.

Ya en el siglo XIX el palacio de tezontle rojo tuvo vida azarosa; en él se proclamó a Iturbide como emperador de México quien lo usó como palacio real, su calidad arquitectónica y su privilegiada ubicación fueron determinantes para que las autoridades eligieran esta mansión para eventos especiales como promulgaciones, juramentos y celebraciones. Luego pasó a acondicionarse como hotel, que llegaría a ser el más elegante de la ciudad, visitado por divas de la ópera, viajeros ilustres, etc.

Los finos muebles originales fueron desapareciendo y se sustituyeron al gusto de las nuevas modas más prácticas y modernas. Papeles, archivos y libros fueron subastados, robados y hasta quemados.

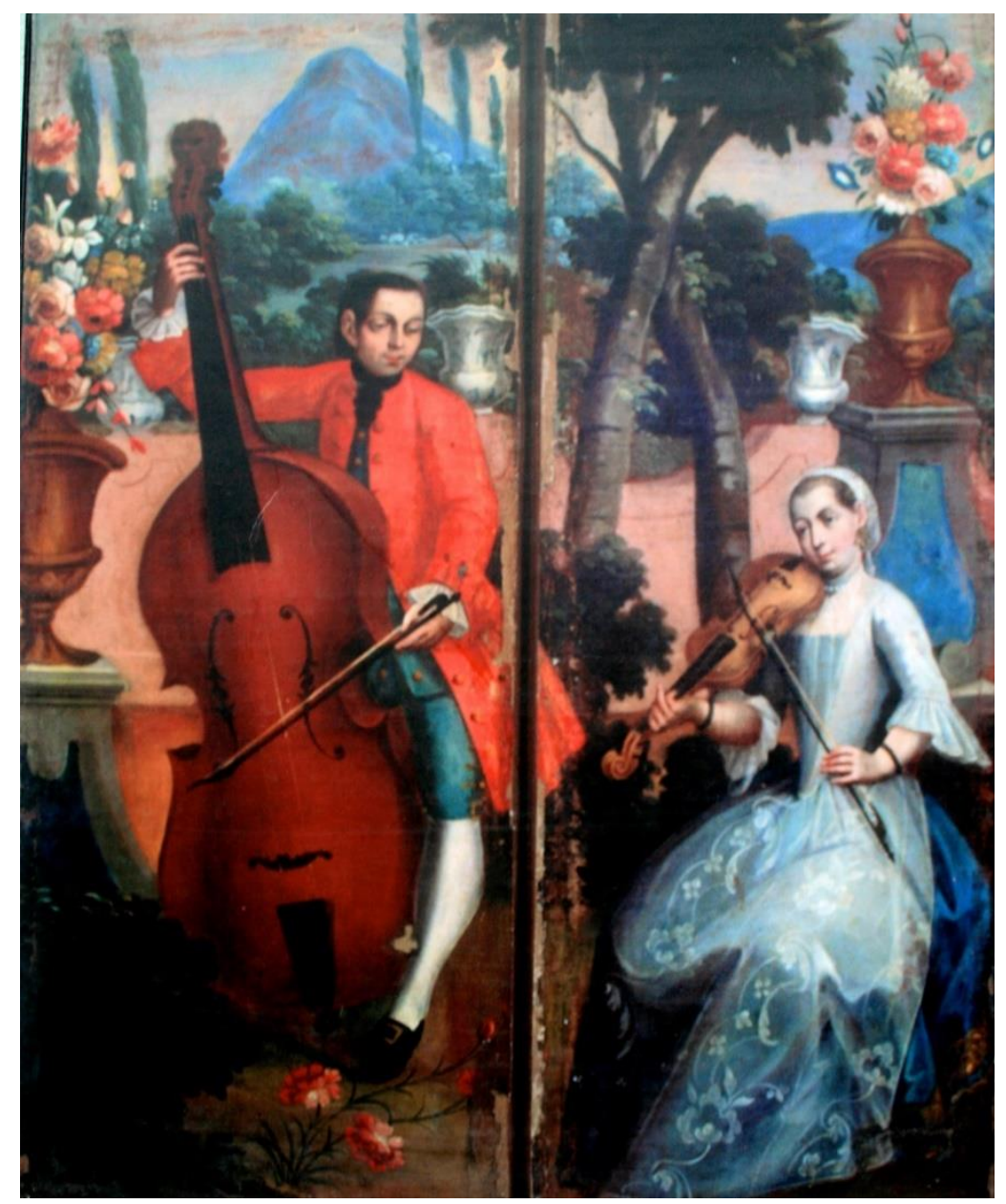

Fig. 3: Biombo anónimo del siglo XVIII. Concierto en la Alameda de México, detalle de tañedores de violón y violín, Museo Franz Mayer. 
Instrumentos y partituras permanecieron en la casa de doña Ana María de la Campa y Cos, condesa de San Mateo Valparaíso y marquesa del Jaral (1716 - 1799), noble criolla que al parecer fue melancólica, afecta a la música y habitó este notable palacio con su mexicanísima fachada de tezontle y piedra chiluca, su sobrio patio clásico con medallones de césares romanos y su dispuesta capilla (que seguramente alhojaría un órgano pequeño), salón de estrado y otras salas para tertulias musicales, el palacio colinda con el convento de San Francisco. El palacio fue construído por el prestigiado arquitecto don Francisco Guerreo y Torres (1727-1792), ilustrado intelectual, acaudalado contratista, maestro de obras en el palacio virreinal, la Catedral de México, autor de la elegante sede de la Inquisición y de varios hermosos palacios entre los que destacan el de los marqueses del Jaral, el del conde de Santiago Calimaya (empleando elementos decorativos prehispánicos) y el suntuoso palacio de los condes de San Mateo Valparaíso.

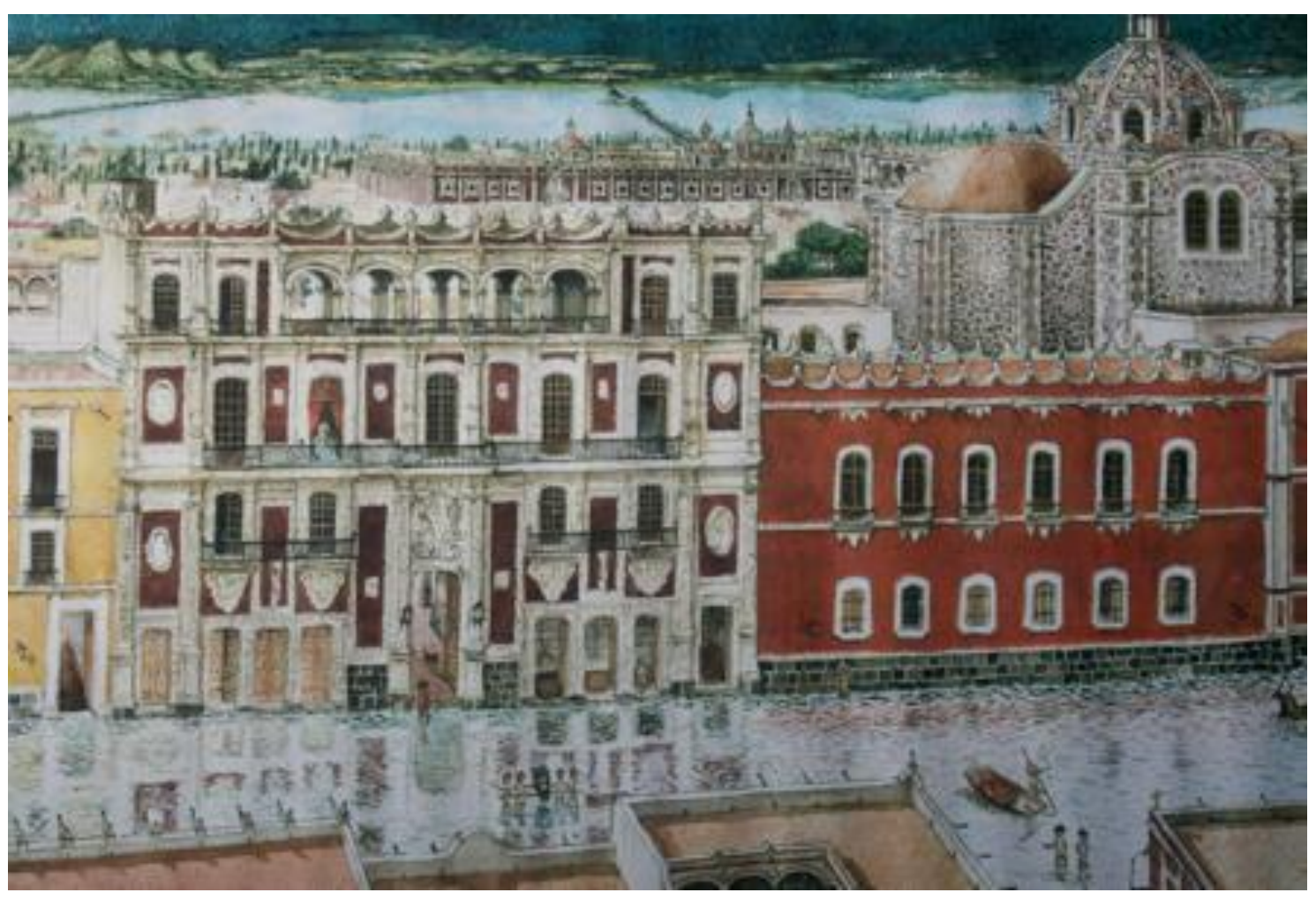

Fig. 4: Palacio del marqués del Jaral de Berrio, obra del arquitecto Guerrero Torres. Dibujo a tinta y colores de Carlos Emilio Teja. Se dijo que fue mandado hacer con lujo de acabados en sus cuatro pisos para evitar que la fortuna del marqués fuera a parar a las manos del marido de su hija doña Mariana, el dispendioso principe siciliano don Pedro de Moncada y Branciforte.

\section{INSTRUMENTOS DE MÚSICA}


Como lo advierte el encabezado de la Memoria, estos bienes existen por no baberse podido vender, lo que implica que algunas ventas previas habrían dado cuenta de piezas previsiblemente las más valiosas en su momento- de las que por el momento tenemos el rastro probado por la numeración discontinua de las partituras y la miscelánea de menudencias como arcos quebrados, puentes de violín, juegos de clavijas, tirantes, tornillos de arco y hasta unas trompas sin boquillas ni tudeles que también presentan el orden salteado de aquello que se ha escogido previamente. Por esto resulta imprescindible el cotejar este listado con las 2 memorias antes referidas. ${ }^{6}$

No se conoce el destino de estos bienes, adjudicados a la propiedad de la viuda marquesa a partir del 18 de febrero de 1785.

Correa (2014) cuenta en el inventario original de dos páginas de extensión, 25 violines de distinta factura y condición donde destacan dos Stradivari, uno de maque negro y otro amarillo, ambos con sus cajas, cuatro Amati y otros instrumentos como un organeto de 2 registros, dos guitarras, trompas, tres violas y dos flautas que ya habían sido vendidos para cuando se realizó nuestra Memoria que sólo posee la lista en una página. Estos instrumentos se habían vendido gracias a la calidad y prestigio de sus constructores así también el índice de las partituras había decrecido de cinco fojas a sólo dos.

Hay que notar que este apartado se inicia con el número 3, es decir, que los instrumentos que portaban los números 1 y 2, (quizá los mejores ) amén del $4,6,7,12,16,17,18,19,20$, y Dios sabe que otros, ya habían sido ya escogidos y comprados por conveniencia de precio y calidad.

Además de la mención de un violín estropeado del lado de la cuarta cuerda, se habla de otro sin autor, encarnado y con caja; de uno de Ycoli nuevo con caja de maqué colorado a 97 pesos, el violín tasado más caro, al que siguen otros firmados por Hieronimus Yrene, Simpson, Guarnerio, Amati y Steiner y también consigna una viola blanca, puentes para violines y violones, además de la susodicha enumeración de menudencias, que revelan el trabajo frecuente de una pequeña orquesta de cuerdas.

A continuación el listado tal como aparecen en el inventario; el precio a la derecha, expresado en pesos de oro de minas y en reales tras el punto:

\footnotetext{
${ }^{6}$ Correa, Alejandro, (2014), Música instrumental del siglo XVIII en la Nueva España. Memoria de instrumentos musicales y piezas de música del marqués de Jaral, SMUC, UAB, Proyecto final del curso 2013-2014. Comunicación del Mtro. Javier Artigas, director de esta tesis para obtener el Máster de Interpretación de Música Antigua.
} 


\section{José ANTONio GuZMán BRAVO}

N.5...Por otro sin Autor, maque encarnado con caxa....... $\quad 060.0$

N.8...Por otro de Ycoli nuevo con caxa y maque colorado.... 097.0

N.9...Por otro Hieronimus Yrene, bien tratado con caxa en... $\quad 065.0$

N.10...Por otro Gateado de Simpson viejo con caxa........ 055.0

N.11...Por otro del Guarnecio maque criollo con caxón...... 045.0

N.13...Por otro cremonense Pardo en................. 040.0

N.14...Por otro maque amarillo con caxa.............. 040.0

N.15...Por otro de Amati con caxa..................................... $\quad 039.0$

N.21...Por otro Stainer colorado, maltratado con caxa...... 020.0

(Sin número) Por una viola blanca sin tirantes............ 002.0

Por varios arcos quebrados......................... 002.0

Por 12 o docena de puentes de violín à 4 rs............... 060.0

Por 13 puentes de violón a 2 rs......................... 003.2

Passa al frente (cambio de hoja)

Suma anterior

Por 14 juegos de clavijas a 2 rs........................ 003,4

Por 11 tirantes de violin a 2 rs........................ 002.6

Por cinco tornillos de arco en....................... 000.32

Por 3 cadejos de serdas en.......................... 000.4

Por varios pedazos de lija en.......................... 000.6

Por unas trompas de Guante sin voquillas ni tudeles......... 015.0

605.12

\section{Papeles de música}

No se sabe cuándo ni dónde irían a parar los instrumentos y las partituras. Una hipótesis que adelantamos es la de que quizá parte de estas obras y algunos instrumentos

\footnotetext{
${ }^{7}$ Gateado adj. Semejante en el color a los mas comunes del gato//m. Madera americana muy compacta y variamente veteada, que emplean los ebanistas en muebles de lujo Diccionario de la Lengua Castellana, Madrid, 1881.
} 
fueron adquiridos por el padre José Fernández Jáuregui e integradas a su patrimonio como puede deducirse del apartado relativo a música antigua en el Abaluo de los papeles de Música pertenecientes al albaceazgo del difunto P. Dn José Fernández. Jáuregui, año de 18018. En este sustancioso inventario de 26 fojas se encuentran listados de sinfonías, sonatas, conciertos, música para el clave y varios instrumentos musicales, entre los que hallamos más de 100 violines de diversas clases, (tal vez algunos provenientes de la casa del Marqués):

Bajo el encabezado de (Música) Antigua, encontramos:

\author{
Albinoni: ob. 10 \\ Corelli: ob. 1, 2, 3, 4, 6 \\ Locatelli: ob. 5, 14, 3, 7, 9 \\ Scaccia: ob. 1 (este músico no aparece en el inventario del Marqués) \\ Tartini: Arte del Arco (no se menciona como tal, sino 12 cuadernos de conciertos) \\ Valentini: ob. 7,1 \\ Vivaldi: ob. 7, 6
}

Aunque esta música en 1801 tendría en promedio, poco más de un siglo de antigüedad, todavía gozaba de aceptación y aún subía de precio como lo sugiere la nota al final del avalúo, así que no es aventurado adelantar que esas partituras darían con buenas manos "Sin embargo, de los precios que en ésta constan por los avaluos, lo que se a bendido de lo dho. À cido en mas de sus precios fechos. Como por menor llevo quenta" (Abaluo, 1801, vol. 1334, f. 53).

Curiosa referencia que sitúa a la Nueva España como un lugar donde se realizan ejecuciones de "música antigua" a comienzos del siglo XIX, quizá no serían ejecuciones históricamente informadas sino adecuadas al gusto contemporáneo de instrumentistas y público.

De una cosa podemos estar seguros con la enumeración de este reparto de bienes; de la gran afición -cultivada desde el suntuoso palacio de la calle de San Francisco, hoy Palacio de Iturbide $-{ }^{9}$ por la música barroca italiana para cuerdas y continuo de la primera mitad del siglo XVIII. Además se registra el interés del marqués del Jaral por la música de moda en la $2^{a}$ mitad del siglo XVIII, compositores galantes y preclásicos entre ellos dos maestros italianos a la sazón trabajando en la Catedral de México, como Ignacio Jerusalem y Santiago

\footnotetext{
8 Abaluo de los papeles de Música pertenecientes al albaceazgo del difunto P. Dn José Fernández Jáuregui, año de 1801. Archivo General de la Nación, (AGN), México, Tierras, vol. 1334, ff. 27-53, comunicación personal del guitarrista e investigador, Eloy Cruz, también citado por Miranda, R. (enero-diciembre, 1997). Heterofonía, vol.xxx, núm. 116-117, pp. 39-50.

${ }^{9}$ Hoy alberga la sede del Centro Cultural Banamex en la calle de Madero \#17.

"Félix Calleja lo habitó mientras se recuperaba del sitio de Cuautla y en sus salones se recibió la noticia de que había sido nombrado jefe político de Nueva España”. Ladd, 1984, p. 95.
} 


\section{JosÉ ANTONIO GUZMÁN BRAVO}

Billoni que frecuentaban las tertulias y que quizá recibieron encargos del marqués para componer música ex profeso para el lucimiento violinístico.

Recordemos que el yerno del marqués don Miguel era un cosmopolita príncipe siciliano, don Pedro de Moncada y Branciforte, caballero de Malta y de San Juan de Jerusalén, cercano pariente del virrey don Miguel de la Grúa marqués de Branciforte (1794-1798). Don Pedro casó con doña Mariana de Berrio y de la Campa a pesar de la fama de Casanova y de manirroto que pesaba sobre él. Se dice que a la postre acabó con la fortuna de su esposa de más de 2 millones de pesos y que ya antes había liquidado sus ville e palazzi en Palermo.

Este singular caballero puede ser uno de los responsables del atinado acopio de partituras, seleccionadas con un fino y moderno sentido del gusto musical y que revelan un encauzado propósito de adquirir los juegos de conciertos, sonatas, oberturas y arias de mejor calidad producidas por entonces en Italia. Este noble, también violinista, contribuyó a reforzar el gusto italiano en el palacio del Jaral con la práctica moderna del violín, tal como la conocería en Sicilia, Roma y Venecia, o simplemente fue el responsable de comprar en Italia algunas partituras, tal vez como regalo a su futuro suegro. Don Pedro finalizó sus días en un elegante palacio veneciano donde fue vecino de Lord Byron. ${ }^{10}$

La presencia de partituras impresas provenientes de Londres, Ámsterdam o París atestiguan la llegada a Veracruz de ediciones modernas aunque la mayoría del acervo consistía en copias manuscritas para uso práctico.

\footnotetext{
${ }^{10}$ Comunicación personal de Guillermo Tovar de Teresa. 


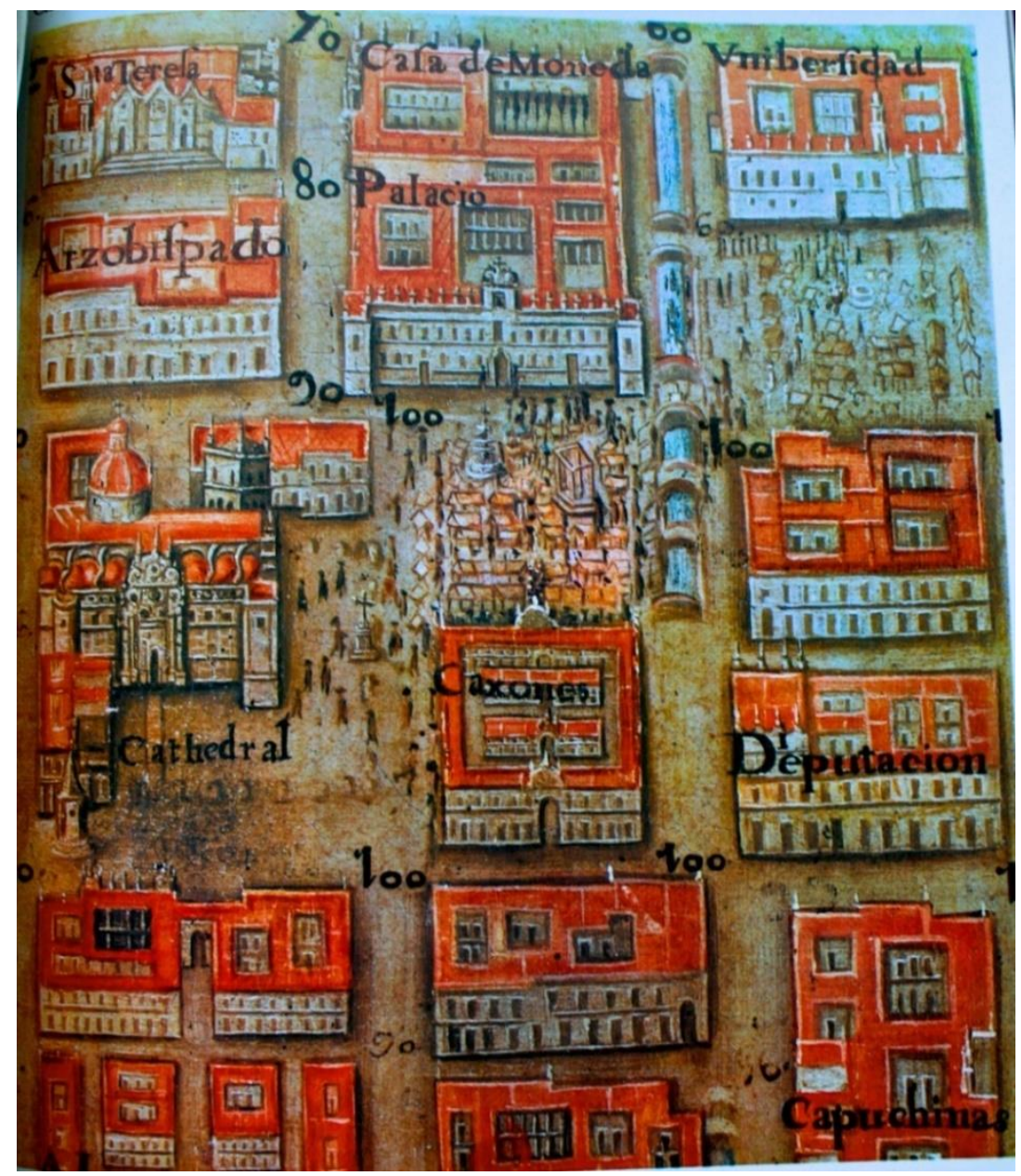

Fig. 5: Plano de la Ciudad de Pedro Arrieta (1737).

El conde don Miguel, como violinista diestro, tocaría algunas partes lucidas con la orquesta y otros miembros o amigos de la casa. Discípulos del maestro de música o algún hábil criado, se agregarían a estas tertulias musicales. Frecuentemente se invitaba a profesionales de ciertos instrumentos, cantantes de renombre, bailarines o a diletantes aventajados para eventos específicos a los que el mismo virrey y el maestro de capilla de catedral, don Ignacio Jerusalén como violinista, asistían. También era invitado don Miguel a convites en el palacio real como el de la noche del 6 de enero de 1758, donde se sirvió un amplio refresco, con la asistencia de muchas señoras de distinción.

Sabiendo SS.EE. la destreza con que manejaba el violín el señor conde de San Mateo Valparaíso, le pidieron que hiciera alarde de su habilidad, lo que practicó con grande aire; y habiendo concluído, comenzó el festejo con un gran golpe de música que duró hasta la media noche (Castro Santa Ana, 1854, vol. 6, p. 217).

La orquesta de cuerdas de la casa condal constaría, como era usual, de dos violines primeros y dos segundos, viola, dos violonchelos y violón, regidos por el clavecímbalo o el 


\section{JosÉ ANTONIO GUZMÁN BRAVO}

realejo de continuos, y dirigidos muy posiblemente desde el violín solista, por el maestro de la casa.

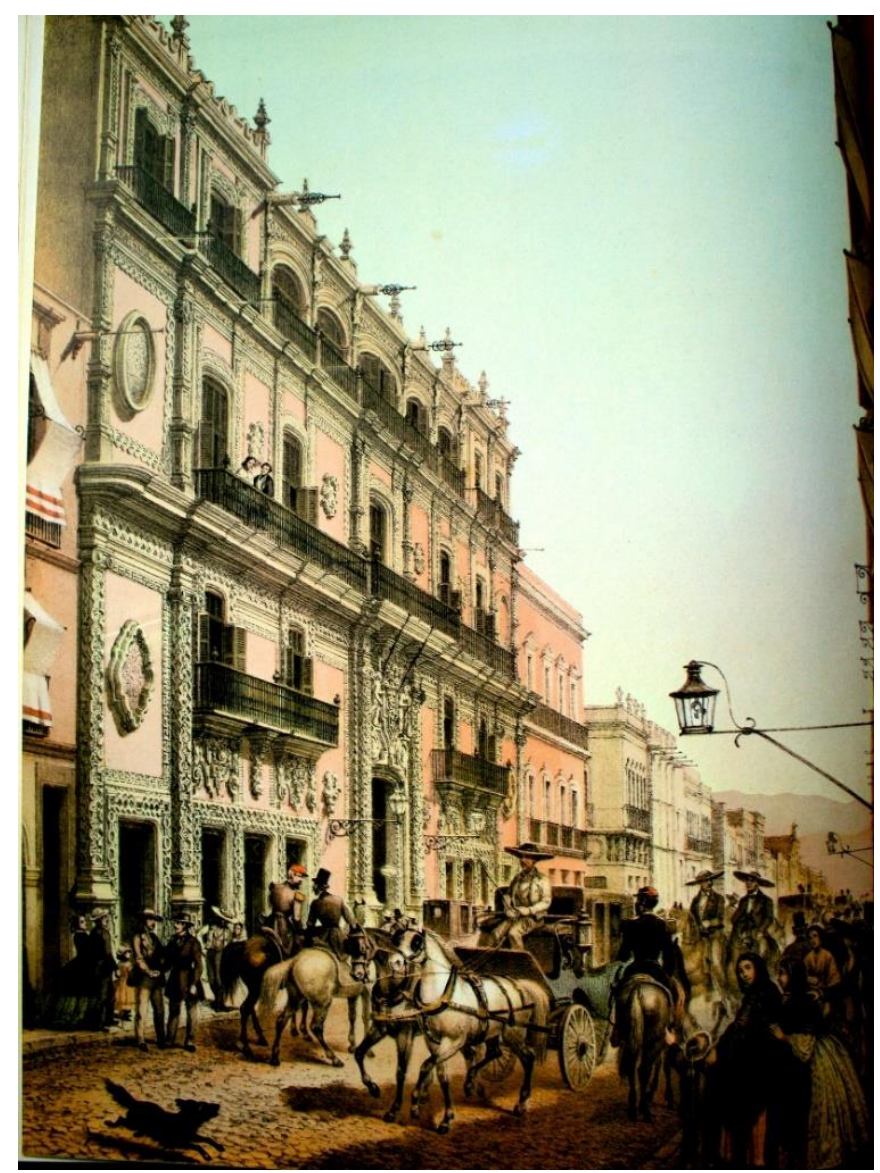

Fig. 6: Casa de los marqueses de Jaral de Berrio a principios del siglo XIX.

Seguramente se emplearon las flautas y las trompas (cornos) como nos indica la Memoria, a los que se podían añadir oboes, clarinetes, fagotes, trompetas y percusiones, imprescindibles para redondear los usuales conjuntos de instrumentos del barroco virreinal, que lo mismo aparecen en biombos, pinturas, esculturas, nóminas eclesiásticas o grabados, que en las descripciones de la vida doméstica, en las crónicas de La Gaceta de México o en las dotaciones que requerían don Manuel de Sumaya, Ignacio Jerusalén o Mateo Tolis de la Rocca, entre otros compositores y músicos que muy posiblemente frecuentaron estas tertulias refinadas. El ilustrado Marqués recibió lecciones del insigne Ignacio Jerusalén a quien aconsejó con buena fortuna que compusiera La Oda a Ntro. Rey Y Señor Don Carlos III, recordándole de paso al Rey que la nación que más le amaba y le servía era por cierto el reino de la Nueva España, por sobre el de Italia y el de España y esto le valió felicitación del Virrey, el excelentísimo señor conde de Galves. 


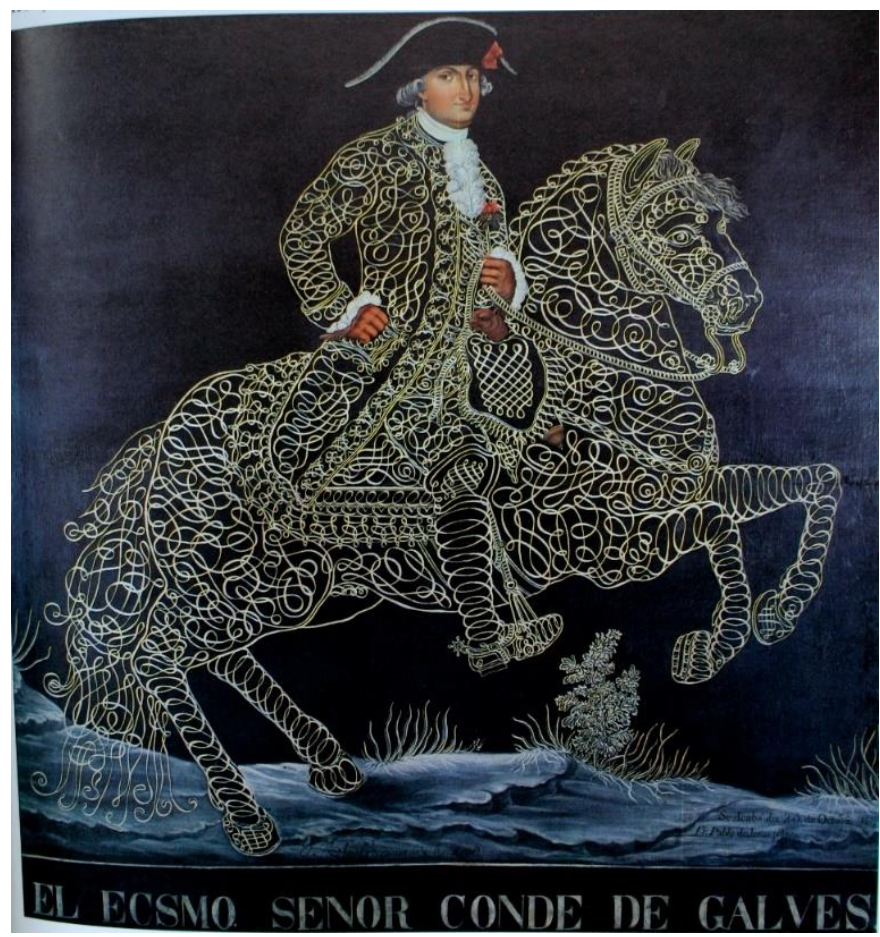

Fig. 7: Retrato del Virrey de Galves, de fray Pablo de Jesús (1796), Museo de Historia del Castillo de Chapultepec.

Un estudio de las nóminas de pagos de servidumbre de la casa, revelará más puntualmente la constitución básica de la plantilla de músicos, rara vez más de 3 o 4, a los que se podían agregar para algún evento especial, músicos de la capilla musical catedralicia y otros recién llegados a la corte. Cantantes, actores y bailarines provenientes del Teatro del Coliseo, también actuaban en representaciones y conciertos, en la privacidad de los salones de esta hermosa casona.

Los gastos de la vida citadina eran muy altos. Una de las razones era que las riquezas atraían cortes de gentes y que muchos nobles mantenían a los parientes pobres y a huérfanos, tanto como sus empleados, capellanes, notarios y costureras. Las grandes casas de la ciudad requerían el servicio de 10 a 20 criados. En 1750 Jaral tenía quince (Ladd, 1984, p. 98).

En este inventario se puede constatar la existencia, en México, de un buen número de obras maestras de la literatura musical italiana, algunas obras españolas y la previsible ausencia de partituras novohispanas (salvo Jerusalem y Billoni, ambos italianos) reflejo del tradicional desdén de nuestras clases privilegiadas por la música nacional.

Conviene la debida cautela para no precipitar conclusiones, ya que este inventario muestra que fue privado sin duda de obras significativas, como se ve en la irregular sucesión numérica. Aunque el rico archivo musical aún da para mucho, por ahora habremos de conformarnos con estas menciones, reveladoras del fino gusto y de la filiación musical francamente italianizante de estos representantes ilustres de la sociedad novohispana. 


\title{
JosÉ ANTONIO GUZMÁN BRAVO
}

Por su importancia en la música de cuerdas con bajo continuo de la segunda mitad del siglo XVII, destaca el nombre de Arcangelo Corelli (1653-1713) representado con un crecido número de sonatas que pertenecen a notables colecciones originalmente publicadas en Italia con los siguientes títulos:

\author{
XII Suonate a tre, due violini e violoncello, col basso per l'organo, Op. 1 (Roma,1681). \\ XII Suonate da camera a tre, due violini, violoncello e violone o cembalo, Op. 2 (Roma,1685). \\ XII Suonate a tre, due violini e arcileuto col basso per l'organo, Op. 3 (Modena ,1689). \\ XII Suonate da camera a tre, due violini e violone o cembalo, Op. 4, (Bologna,1694). \\ XII Suonate a violino e violone o cembalo, Op. 5 (Roma 1700).
}

Quizá el autor mejor representado en esta colección es Antonio Vivaldi (1675-1741), de quien se encuentran sus obras instrumentales más reconocidas: Los conciertos del Op. 3 L'estro armonico, Op. 4 La stravaganza, Op. 8 Il Cimento dell'A rmonia e dell'Inventione (En cuyo libro $1^{\circ}$ se encuentran las célebres 4 estaciones), Op. 9 La Cetra y una copiosa lista miscelánea de concerti e sonate, que hoy en día resulta imposible precisar.

Lo mismo sucede con las inquietantes y dilatadas menciones de libros antológicos (aunque no contamos con los nombres de los autores) que dan pié a cualquier número de suposiciones: 41 Conciertos de varios autores, 36 sonatas de varios autores, 1 cuaderno con 6 solos de flauta italianos, 1 cuaderno con 6 sonatas de violín, Solos y divertimentos de varios autores, Partida de Minuetos de tocary cantar, 3 Salves una a duo y 2 a solo, 90 Arias y Duos de varios autores, 57 arias a 2 reales, 64 Conciertos y sinfonías de varios autores, 6 de tres instrumentos y unos duetos, 11 oberturas viejas y una Aria (Memoria, 1782).

Este apartado contiene además mención castellanizada de otros compositores de primera línea como Galupi, San Martino, Alberti, Geminiani, Tartini, Locateli, Albinoni, Toreli, Veracini, Bocherini y un enigmático Jaen (sic) Christian (¿Bach?). Además de estos reconocidos autores aparecen otros, quizá notables en su momento (como el celebrado Farinelli) pero que ahora resultan curiosidades musicológicas, como por ejemplo: Bernasconi, David Pérez, Prota, Briosqui (Farinelli), Contihulini, Pla, Lampigniani , Scalaschi, Valentini, Laurenti, Mota, Palavichini, Faco (cuyas obras aparecieron también en el archivo musical del Colegio de las Vizcaínas), Herteli, Mosi, Villoni (mencionado en el archivo de la catedral de Durango), Andrea Marra, Puñaniy Ben.

Una considerable biblioteca musical, digna de un destacado diletante.

Además de sugerirnos un nivel de ejecución elevado que se requiere en obras de muy arduo virtuosismo, la colección nos revela un gusto moderno y sofisticado que valoraba el arte violinístico italiano, las obras vocales, los abundantes solos de flauta y la música de cuerdas concertada con bajo continuo como los más altos logros del barroco. 


\section{INVENTARIO QUE CONTIENE INSTRUMENTOS Y PAPELES DE MÚSICA,}

MÉXICO, 1782

A continuación un listado de los papeles de música como aparecen en el inventario, nótese la numeración que comienza en el $\mathrm{N}^{0} 9$ y que ocasionalmente se rompe, denotando la venta o salida de esa partitura del inventario.

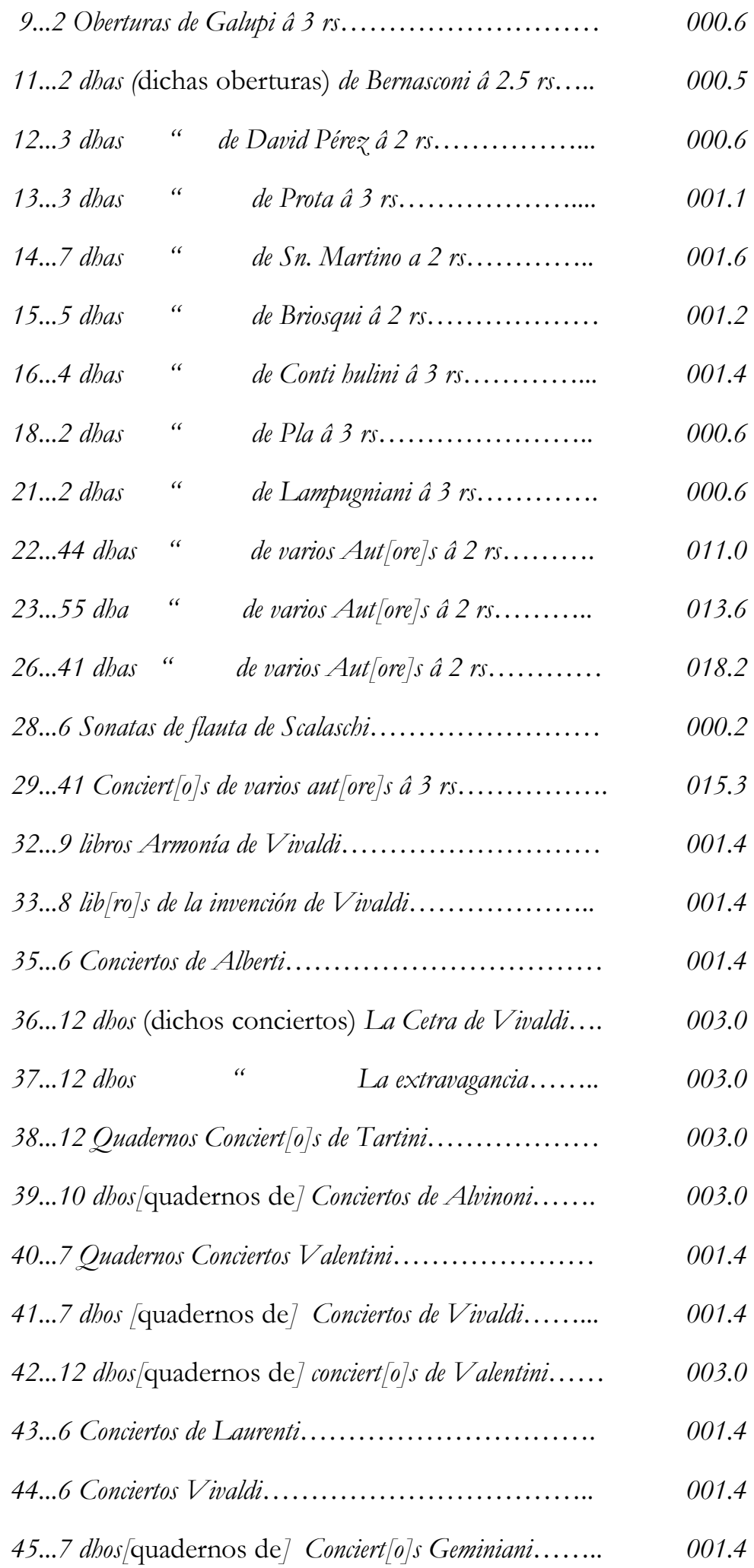




\section{JosÉ ANTONIO GUZMÁN BRAVO}

46...4 dhos[quadernos de] Conciertos de Vivaldi...

001.4 .

088.5

Passa â la v [uel]ta

Por la v[uel]ta

088.5

47...36 Sonatas de varios aut $[$ ore $]$ s en...................

004.4

49...10 Quadernos Sonatas de Locatelli................. 006.0

$50 \ldots 5$ dhos (quadernos de) Sonatas Tartini............. 000.6

51..5 dhos " Sonatas de Coreli................ 003.0

52...6 dhos " Conciertos de Mota.............. 002.0

53...4 dhos " Sonatas de Valentini............ 003.0

54...12 dhos " Conciertos de Palavachini........ 003.0

55...12 dhos " Conciertos de Faco.............. 003.0

56...16 dhos " Conciertos de Valentini............ 003.0

57...6 dhos " de Jaen Christian............... 001.4

58...5 dhos " Conciertos Valentini.............. 003.0

59..3 dhos " con 6 Sonatas à 3 de Coreli......... 001.4

60...7 dhos " de Conciertos de Albinoni.......... 003.0

61...18 dhos " Estro Armonico (Vivaldi)......... 003.0

62...7 dhos " de Vivaldi Torreli............... 001.4

63...12 dhos " Conciertos de Valentini........... 002.4

64...4 dhos " con 6 de flauta de Locateli.......... 001.4

$65 . . .3$ dhos " con 48 trios de Coreli............. 006.0

66...1 dho " con 6 Sonatas de Herteli........... 000.6

67...1 dho " con 12 Solos de Mosi............. 001.4

68...1 dho " con 6 Solos de Albinoni........... 000.6

69...1 dho " con 6 Solos de Maltier............. 000.6

$70 \ldots 1$ dho " con 6 Solos de flauta Ytalian $[0]$ s.... 000.6

72...1 dho " con 18 duos de flautas.............. 002.4 


\section{INVENTARIO QUE CONTIENE INSTRUMENTOS Y PAPELES DE MÚSICA,}

MÉXICO, 1782

$73 . . .1$ dho $\quad$ con 12 Solos de Villoni.............
$74 \ldots 1$ dho " con 12 Solos de Mosi.................
$78 . .8$ dhos " conciertos $y$ duos de Alverti............

77...1dho " con 12 solos de flauta de A. L. F. B. 004.0

79...7 Sonatas de Andrea Marra........................ 005.2

80...1 Sonata de Coreli............................ 009.0

81...1 ..6 Sonatas de violín a 5 rs...................... 003.6

84...1. La $5^{a}$.opera de Coreli............................ 003.6

85...1 Exemplar de las anteriores..................... 003.6

86...12 dhos de Geminiani............................ 003.0

87...6 dhos de Veracini............................... 003.0

$88 . .6$ dhos de Puñani............................. 003.0

89... Solos y divertim [iento]s de varios aut [ore]s............ 001.4

91... Partida de Minuet [o]s de tocary cant $[a] r . . . . . . . . . . \quad 001.4$

92...3 Salves una à Duo y dos à solo................... 003.0

93... 90 Arias y Duos de varios aut [ore 7 s à 4 rs........... 045.0

$94 \ldots 57$ dhas [arias] à 2 rs......................... 014.2

95... 64 Consiertos y Sinfonías de varios aut [ore $]$ s à 3 rs. $=6$ de 3 instrumentos à 2 rs. y unos duetos en 1 p [esos] q[u]e todo imp [or]ta 026.4

106..6 Duos de Bocherini en.......................... 004.4

108... 7 dhos $[$ duos $]$ de Ben.......................... 007.6

Passa al frente 296.3

Por la de enfrente 296.3

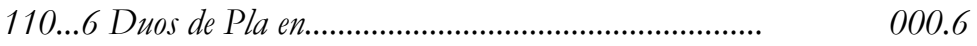

115... 11 Oberturas viejas y una Aria....................................

5 Manos de papel pautado averiado à 10rs......... 006.2

20 pliegos de marca à12rs................................. 003.6

20 dhos [pliegos] mas chicos à 7 rs....................... $\quad 002.4$ 


\section{JosÉ ANTONIO GUZMÁN BRAVO}

\section{MÚSICA Y SOCIEDAD}

Nos hemos referido en este artículo a la práctica musical desarrollada en la segunda mitad del siglo XVIII por un limitado grupo de aristócratas novohispanos que como don Miguel de Berrio y Saldivar pertenecían a una clase ilustrada que practicaba la música de moda en la Europa contemporánea. México entonces era un virreinato o provincia privilegiada del Imperio Español. A diferencia de los avatares económicos que sufría la península, en la Nueva España, el rendimiento de las fabulosas minas de plata, las enormes haciendas ganaderas y agrarias, los privilegios y licencias para el comercio hicieron crecer las grandes fortunas de españoles peninsulares y españoles americanos, llamados criollos que se esforzaron por acceder a los principales puestos eclesiásticos, administrativos, artísticos y económicos, reservados para los peninsulares. Pero ambos representaban una minoría o élite ilustrada que acaparó los cargos disponibles en la cultura y en la ciencia. Los indígenas, mestizos, castas y negros, tenían vedados los accesos a puestos de importancia y responsabilidad. Aunque en la Catedral y principales parroquias de la ciudad hay presencia de estas etnias, solamente los indígenas "legítimos" recibieron algún tipo de privilegios reservados, como poder portar espada, montar a caballo, vestir a la española o construír órganos.

Es quizá esta segregación cultural, esta distancia entre la música popular y música culta lo que alejó a una buena parte de la sociedad de estas formas y tipos de música, que sólo se escuchaba en los colegios, teatros y salones palaciegos, donde solamente entrarían como sirvientes o acaso como instrumentistas requeridos y capaces. En la Catedral y otras iglesias se ejecutaba ocasionalmente música instrumental como oberturas, conciertos y sonatas, y sería una de las pocas oportunidades de una crecida población para escucharla. Así la brecha insondable que separó a las clases sociales se ahondó con el auge de las clases privilegiadas que podían permitirse el ejercicio no remunerado de las artes y la música.

El desdén típico de las clases altas por lo popular y lo autóctono que les resultaba de "mal tono" se deja ver en la orientación francamente europeizante de estas clases que soñaban con emparentar con la nobleza española, italiana o francesa, haciéndose de títulos que ahora la administración real dispensaba a las grandes fortunas coperativas y leales a la corona.

En Nueva España aún no se generaba como en Europa, una burguesía o clase media que fuera destinataria de esta "música culta" y los aristócratas diletantes resultaron los beneficiarios de estos géneros musicales vedados a la mayoría.

Habrá de pasar casi todo el siglo XIX para que esta música extienda su difusión a través de conservatorios y escuelas de música, y llegue a ser patrimonio cultural compartido, aunque manteniendo su carácter elitista de música urbana, practicada por clases sociales educadas y desahogadas económicamente.

Quizá estas son algunas de las razones por las que el cultivo de las formas cultas puramente instrumentales como sonatas, sinfonías, conciertos o cuartetos, se haya producido en ambientes restringidos de especialistas o músicos profesionales y expliquen, al menos 


\section{INVENTARIO QUE CONTIENE INSTRUMENTOS Y PAPELES DE MÚSICA,}

\section{MÉXICO, 1782}

parcialmente, las dificultades de una aceptación general y del escaso cultivo que de ellas se hizo en nuestro país.

\section{BIBLIOGRAFÍA}

Abaluo de los papeles de Musica pertenecientes á el Albacenazgo del difunto P. Dn. Jose fernandez. Jaureguil año de 1801. Archivo General de la Nación, Tierras, 1334.

Arriaga, G. (1982). Un manuscrito mexicano de música barroca. Revista de Musicología, vol. 5, 1, pp. 111-126.

Castro Santana J. M. (1854). Diario de sucesos notables y comprende los años de 1754 a 1756. En Documentos para la Historia de Méjico, T.6. México: Juan R. Navarro.

Correa, A. (2013-2014). Música instrumental del siglo XVIII en la Nueva España. Memorias de instrumentos musicales y piezas de música del marqués de Jaral. (Proyecto Final). Barcelona: SMUC, Universitat Autònoma de Barcelona.

Cosio Villegas, D. (Coord.) (1981). Historia general de México, 2 vols. México: El Colegio de México.

Diagram Group (1978). Musical Instruments of the World: An Illustrated Encyclopedia. Nueva York: Bantam Books.

Díez Canedo, M. (2007). La flauta travesera en las dos orillas. Una sonata de flauta de Luis Misón en México. Cuadernos de música iberoamericana, 14, pp. 41-72.

Florescano, E. \& Gil, I. (1976) (Comp.). Descripciones económicas regionales de Nueva España. Provincias del Centro, Sureste y Sur, 1766-1827. México: INAH.

Enríquez, L. (2007). 34 sonatas de un manuscrito anónimo del siglo XVIII, Nueva España (facsimilar y versión Urtext). México: IIE, UNAM.

Gembero Ustarroz, M. \& Ros-Fábregas, E. (Eds.) (2007). La música y el Atlántico.relaciones musicales entre España y Latinoamérica. Granada: Universidad de Granada.

Gómez García, L. \& Mauleón, G. (2008). Las capillas musicales en los pueblos indios del obispado de Puebla. Puebla: BUAP. 


\section{José ANTONIo GuZMán BRAVo}

Guelberof Hann, L. (2006). Archivo de música de la Colegiata de Guadalupe de México. México: Insigne y Nacional Basílica de Guadalupe.

Guzmán Bravo, J. A. (1984). La Música de México, I. Historia, 2. Periodo Virreinal (ed. Julio Estrada). México: IIE, UNAM.

Hernández Monterrubio, M. (2001). José Manuel Aldana: hacia un nuevo panorama del siglo XVIII. Heterofonía. Revista de investigación musical, 125, pp. 9-30.

Herrera, J. (2001). El Quaderno de Guadalupe Mayner. Música para teclado del clasicismo en México. Heterofonía. Revista de investigación musical, 125, pp. 51-62.

Koegel, J. (1997). Nuevas fuentes musicales para danza, teatro y salón de la Nueva España. Heterofonia. Revista de investigación musical, 116-117, pp. 9-37.

Laad, D. (1984), La Nobleza Mexicana en la época de la Independencia, 1780 - 1826. México: F.C.E.

Manrique Figueroa, C. (2008). Libros, lectores y bibliotecas del México colonial. Iberoaméricaglobal, vol. 1, 3, pp. 190-200.

Marín López, J. (2007). Música y Músicos Entre Dos Mundos: La Catedral de México y Sus Libros de Polifonía (Siglos XVI-XVIII), 3 vols. (Tesis Doctoral). Granada: Universidad de Granada.

Maza de la, F. (1985). La ciudad de México en el siglo XVII. México: F.C.E., SEP.

Miranda, R. (enero-diciembre, 1997). Reflexiones sobre el clasicismo en México (17701840). Heterofonía, XXX, 116-117, pp. 39-50.

Memoria de los bienes que existen por no haverse podido vender de los q[u]e quedaron [por la] muerte del Sor. Marqués del Jaraly se aplicaron à la Sra. Condeza su muger el día 31 de Julio de 1782 en q[u]e se hizo la división de caudales.

Reyna, M. C. (2002). Opulencia y desgracia de los marqueses de Jaral de Berrio. México: INAH.

Rubio Mañé, J. I. (1992). El Virreinato, 4 vols. México: IIH, UNAM, F.C.E.

Roubina, E. (2009). Los instrumentos de arco en la Nueva España. México: CONACULTA.

Saldivar y Silva, G. (1987). Historia de la música mexicana, épocas precortesiana y colonial. México: SEP. 


\section{INVENTARIO QUE CONTIENE INSTRUMENTOS Y PAPELES DE MÚSICA,}

MÉXICO, 1782

Saldivar y Silva, G. (1991-1992). Bibliografía mexicana de musicología y musicografía, 2 vols.

México: CENIDIM.

Stein, S. \& Stein, B. (1970). La herencia colonial de América Latina. México: Siglo XXI.

Thornton, P. (1968). Musical Instruments as Works of Art. Londres: Victoria \& Albert Museum.

Vasconcelos, J. (1937). Breve Historia de México. México: Botas.

Fecha de recepción: 28/08/2019

Fecha de aceptación: 04/11/2019 